\title{
Analysis on the Work Practice of College Counselors under the Concept of Fine Management
}

\author{
Rong Chang \\ Tianfu College of Southwestern University of Finance and Economics \\ Chengdu, China 621000
}

\begin{abstract}
China's colleges and universities attach great importance to ideological and political education of students, and college counselors are directly responsible for ideological and political work of college students. On the basis of drawing lessons from the connotation and characteristics of fine management in other fields, this paper tries to analyze the practical methods and effects of counselors in colleges and universities. This is good for fine management work of our college counselors, and thus enhances the work quality of college counselors for students' ideological and political education.
\end{abstract}

Keywords—college counselors; student work; fine management

\section{The EnLightenment of Fine MANAGEMENT} CONCEPT ON THE STUDENT WORK OF COLLEGE COUNSELORS

Fine management is a concept and a kind of consciousness. As mentioned in Wang Zhongqiu's Fine Management: "fine management is a hurdle that Chinese enterprises (including all public institutions and governments of management attribute) shall surmount. Without fine management, it is impossible for any industry and enterprise to stand in an invincible position in the increasingly fierce international competition"[1]. The concept of fine management has been learned and transplanted by other fields. Domestic colleges and universities have begun to try to learn. But at first, the implementation of fine management has met a lot of obstacles. Dr. Yang Xiangui believes that universities and enterprises are of different characteristics, mainly because university is an academic organization, advocating academic freedom. Teachers often cooperate, but they teach and make research individually. They need to show themselves one by one. The "products" of university are high-quality talents which need a rigid system and a lot of flexible emotions. In this way can university of public cause produce ideas, spirits and academic products. At the same time, it is only suitable for qualitative evaluation, and can not be evaluated quantitatively as the products produced by enterprises [2]. Through continuous trial in colleges and universities, it concludes that just follow the law of education and the characteristics of university, fine management is also suitable for colleges and universities, especially in management work of college counselors. That is counselor's fine management work on students. In the

This article is one of the stage achievements of the school-level project in 2017: Present Situation Analysis and Countermeasure Research of College Student Management under the Background of University Transformation. Project category: management innovation; Project level: key project; Item number: TFC2017ZD01. opening ceremony of college counselor training and advanced seminar organized by the Fujian Provincial Education Committee, the Fujian Provincial Department of Education and the Ministry of Education, Guo Shaosheng, deputy secretary of the Provincial Education Committee and party member of the Provincial Department of Education said: "to carry out fine management on students' ideological and political education is to adhere to the principle of delicate, diligent, and earnest work, to aim at students' needs of aspect with enthusiasm and love. To carry out fine management on students' ideological and political education requires to complete rules and regulations, to subdivide working groups, to highlight direction of problems, to standardize the operation procedures and to strengthen pragmatic research". It can be seen that fine management concept has an important role in strengthening the ideological and political education of college students and comprehensive training of all development of their moral, intellectual, physical, aesthetic and labor education. It has been tried to popularize in colleges and universities.

As a special social group, the ideological and political attitude and behavior of college students are directly related to the development and stability of school and society. College counselors, as the backbone in the ideological and political education of colleges and universities, are main power of college and university to give moral education and carry out the ideological and political education. They are guider and leader of college student for healthy growth [3]. They play a key role in the implementation of quality education. Therefore, to carry out fine management on students work is not only a way to improve the effect of ideological and political education on college students, but also a certain choice for counselors to improve their work efficiency and make full play of their role in humanistic care and psychological counseling.

\section{THE CONNOTATION OF FINE MANAGEMENT FOR COLLEGE COUNSELORS}

Taylor, the father of scientific management, has written the Scientific Management Principles in 1911. It was regarded as the world's first works on fine management. Subsequently, the real impact on the formation of fine management thinking was the Japanese enterprise management model -TOYOTA production methods (referred to as "TPS") with lean production as goal. This mode of production can constantly 
improve production efficiency, eliminate the unnecessary waste in production to the maximum, and constantly look for improvement methods to promote the rapid development of enterprises. Later, this management concept has also been introduced into China's extensive management of some enterprises. Wang Zhongqiu, the first person of Chinese fine management, put forward that fine management is premised on professional, guaranteed by technology and standardized by data and with information as means. It concentrates the focus of server onto meeting the needs of client thus to gain higher efficiency, more benefits and stronger competition [4]. Fine management is a management style with the target to minimize the resources and reduce the cost of management. It has been ported to other areas. It has to be delicate, accurate and strict. To be delicate means to do management delicately and pursue the best. It requires to do service and management work to the best and challenges the limit. To be accurate includes accurate information, accurate decision, accurate data and measurement, accurate timing connection and correct working methods. To be fine means to have direction. To be strict means to implement strictly. It is mainly reflected in the implementation and control of management systems and processes. It is a serious attitude, a fine behavior, a deep culture.

In fine management, counselors should take "fine" and "delicate" as core. It is a construction of university culture. It adheres to the goals of taking the development of students as root, improvement of abilities as main line and dissemination of knowledge as carrier". It emphasizes on informatization, datamation and networked methods to carry out fine management. It aims to achieve maximum benefit and service optimization in student management substantially [5]. Take the student management of a university as an example. In this university, the counselors perform the comprehensive responsibility system and the first-asking responsibility system. The comprehensive responsibility system requires counselors not only to do well in students' daily affairs, but also to give a comprehensive guidance to students in their career planning and development and psychological dynamics. The first-asking responsibility system requires counselors to positively help and solve difficulties and problems that students meet. If counselor has no right to process, he/she should actively contact relevant responsible person or department to solve it, till the problems are properly handled. They implement the real-name registration system and Oracle-system login integration in attendance management. It ensures the integrity of the student information system, provides the basis of tracking, feedback and evaluation for the fine management of students, helps clarify the responsibilities of class organizations and improve the quality of students work.

\section{THE PRACTICAL METHODS OF COLLEGE COUNSEloRS UNDER THE CONCEPT OF FINE MANAGEMENT}

The fine management of counselors' work mainly includes the refinement of students work goals and the refinement of student management process.

\section{A. The Refinement of Student Work Goals}

In the first place, refine the goal of imparting knowledge and educating people. First, we should adhere to the cultivation of talents as the center, and train talents with "one mind, two tools, three habits, four qualities", that is, to train "applied and comprehensive" talents. "One mind" is to establish a correct world outlook and outlook on life. Students should have solid professional knowledge and good humanistic quality, with international vision and innovative thinking and financial mind. "Two tools" means that students could use foreign language and information technology skillfully. "Three habits" is to cultivate students with the habits of self-confidence, self-discipline and self-study. "Four qualities" is to shape students with qualities of filial piety, the sense of honor, integrity and diligence. Second, adhere to the educating concepts of "appreciation education" and "hunting field". Teachers appreciate, encourage and guide students, and students set up confidence. It arouses students' inherent potential and stimulates their motivation of learning and work. Students constantly increase experience and grow in the process of learning and work. At the same time, advocate teachers to set up a hunting field consistent with workplace rules in the teaching activities for students to guide students to experience the law of jungle and get survival skills. Teachers should teacher students how to fish and give up the spoonfeeding educating mode. Third, insist on carrying out classroom teaching reform, and actively implement "Athensstyle teaching". Whether in classroom teaching or classroom management, teachers should change the teacher-centered teaching mode and implement Athens-style, case-style and experience-style and project-driven teaching management mode to strengthen the dominant position of students and enhance their self-study ability. Fourth, adhere to the students' career development as the goal and the improvement of comprehensive ability as main line to design personnel training program. Determine the professional goal and set up courses according to the investigation of the social and market-related job requirements and annual evaluations of employers on students' ability. Not only pay attention to the training of the students' practical employment ability, but also to the development of students' professional ability, and strengthen the training of EQ and develop students' knowledge, ability and quality in a coordinated way. Fifth, adhere to teach students in accordance with their aptitude, and explore the stepped talent-training model. According to the social demand for talents, pilot the stepped talent-training mode in some specialties. Start from freshman, and attract students to participate in through professional clubs and lectures, and thus cultivate interested students with a certain foundation. Then split into two parts. Most of student could become comprehensive talents by selecting many other professional courses. A small number of students, as a professional laboratory research assistant, could become professional talents with innovative ability after guidance of professional mentors. Sixth, evaluate and assessment students in a comprehensive manner. Level of knowledge can not be used as the only index to assess students. Social practice, time management, teamwork and other assessment indicators should be also included to cultivate high-quality talents. 
In the second place, refine the management of educating goal. First, adhere to the concept of all-round education, and build an all-round and whole-process educational environment of "a small society, a large class" with all staff participated. In the campus simulate a real social scene, and let students with management abilities to act as "the small society" and student supermarket and student associations to act as "big enterprise", and management them according to "market demand". Construct an educational environment with administrative personnel, teachers, counselors, students assistants and persons in charge of logistics services participated, in learning, life and work, penetrating in class, outside class and in practice in the whole teaching process. Second, adhere to the humanistic care concept of "caring for the soul and refining heart". Care for the soul, as love life. Refine heart as exercise body in whole life. Pay attention to the cultivation of students' EQ, set up psychological counseling and perfect the mechanism of crisis intervention. Carry out time management, emotional management, and stress management training, so that students may have a sunny mind. Third, peer learning is an important way of learning for college students. Create a good atmosphere for the students' peer learning, and arrange different professional students in a bedroom and students of different grades in the same building, forming a campus atmosphere of mutual learning and mutual exchange. Fourth, self management is the most experiential management in the university. Let students experience all they can do. It can provide a broad space for self management of students and train students' abilities outside classroom. Fifth, adhere to the system management and design flexible space in the system. Establish a comprehensive, clear and rigorous system without losing humanity and having certain elasticity.

In the end, refine the service of educating people. First, adhere to the principle of "full-responsibility system" in management and service. Full responsibility system is different from the post responsibility system. It require each person to care the whole process and base on own position". Counselors should not only do a good job, but also pay attention to the development of things from the beginning to the end, and can timely support and help other staff. Second, adhere to the first-asking responsibility system. It is in a favor of giving better service to students.

\section{B. The Refinement of Management Process of Student Work}

First, refine the management model. Learn from the management model of Oxford and use the procedural, standardized and data-oriented methods to form a precise, efficient, coordinated and sustained working model of counselors. Form a district system like Oxford's college system. In the district system, there are two keys. The first key is to support general enrollment. Otherwise, students have to change bedroom, class, counselor and society when they change major. The second key is to promote peer learning to broaden students' scope of knowledge and enhance their overall quality. District system can be an Oxford college system with Chinese characteristics. This management mode can realize the district system of student accommodation with dormitory building as entity and the construction of special administrative classes and teaching class in matrix organization. Divide into five districts, District A, District B, District C, District D and District E, for student management. Each district is composed by students of one dormitory building or more. When the freshmen enter into school, they will be randomly assigned to each district according to the cross-origin, cross-discipline and cross-subject principle, forming a fixed administrative class. In the teaching process, construct a relatively dynamic teaching class according to the nature of the course, the level of students and professional characteristics. The purpose is to create an atmosphere of communication among students in different majors, and form a platform of complementary knowledge and knowledge sharing. It is conducive to the training of compound talents and the construction of students' interpersonal resources network, and also to facilitate mutual learning among peers. Counselors are also of area-divided management, breaking the traditional management model of colleges and universities. At same time, counselors enter the student building for office. But they are different from the building managers. Only in this way can the effective operation of the student work and area-divided management in the whole campus be ensured.

Second, refine the management content. From the scope, adhere to the principle of non-discrimination and full coverage. Counselors usually pay attention to two types of students. One is the excellent students and the other is the students with family-financial difficulties or psychological problems, and neglects other students. In fact, the other students are main body counselor should pay attention to. They cannot be neglected, and counselors should manage them fine. As for the two types of students, students with difficulties or problems are not unchangeable. After counselor's fine management, they gradually transit to the middle group. Students with problems are often middle-group students outside the sight of counselor and without guidance. Therefore, in order to help problem students from the essence, student counselors should keep the fine management concept into mind. They can guide students one to one. It is the refinement of counseling scope. At present, the objective status quo is that the proportion of counselors to students is low, and many counselors are also engaged in several jobs. Counselors tend to be more than willing and unable to do so in refinement of counseling scope. The direct methods to solve this contradiction: the first is to strengthen the construction of counselor team, and make college counselors become a professional team with a certain scale and high quality. Secondly, try not to arrange counselors to be engaged in administrative work outside student counseling, so that they may have more time to go deep into student counseling. From depth, adhere to individualized teaching and the differentiated treatment principle. Talk with students and counsel students according to their characteristics and needs. For example, some students are interested in handicraft workshop. We can recommend them to participate in the learning and exchange of Zhiyuan Workshop. There, specialized teachers can give them guidance. Some students interested in social activities can be guided to the Federation of Associations and join the corresponding association. Students' enterprise can provide students with the opportunity of business operation to exercise them. Some students come from a poor family. They are often 
hard-working. We can provide them jobs in library and other departments to participate in work study. So that, we can give individualized teaching and differential treatment, and help students develop in an all-round way. Fine management requires diverse counseling methods for different needs of students, and to achieve a certain effect. Besides face to face talk, we can also make use of network resources such as campus network, post bar, QQ, WeChat and so on to guide students' thinking correctly. The most important method of indepth counseling is full coverage in a comprehensive effort. Adjust methods according to the situation, make student satisfied and give them a sense of belonging.

Third, refine the quality of management. Counselors shall follow the quality management process control documents. With the help of student management website platform, clarify counselors' work duties. It can record counselors' daily work timely and remind them work content, remind students work points and reflect daily work of counselors. Design all basic affairs of counselors in each workflow in accordance with program file, introduce the workflow and make counselors' work scientific, reasonable and standard.

\section{THE EFFECTIVENESS OF Fine MANAGEMENT OF COLLEGE COUNSELORS ON STUDENTS WORK}

\section{A. The Full Implementation of the Concept of Educating People}

The implementation of fine management on student work is a good way for colleges and universities to realize the training goal of taking students' development as root, the improvement of abilities as main line and the dissemination of knowledge as carrier, and achieve the whole-process and allround educating-people goal of "a small society, a big class" with all staff participated, and establish the humanistic awareness of caring soul and refine heart. Fine management of counselors is the need of students' daily management. It requires standard and strict management on students' entrance education, ideological and political work and safety education, study-style and class construction, construction of dormitory culture, extracurricular activities and practice guidance. They are not only basic work in student management but also important works to train students to develop habits of selfconfidence, self-discipline and self-study and qualities of honor, integrity, diligence, loyalty and filial piety.

\section{B. Making Area-divided Management Come into Effect}

The effect of the fine management of counselors is also embodied in area-divided management. It breaks the traditional restriction of departments, grade, classes and specialties in building management. Implement the areadivided management and take students' development as center, counselor as point and student cadre as line and district building as face to realize mutual management and highlight district characteristics. It effectively respects and highlights the dominant position of students. In the system of areadivided management, counselors work in students' building. It promotes a strong development of student work. Gradually build the student building into a base of spiritual civilization and education. Greatly improve students' a sense of honor and sense of belonging. Create a conformable and positive culture atmosphere in the building, and make students' spiritual and cultural style reveal in life. It helps form a three-self education base, and students and counselors can participate in democratic area-divided management. It helps students implement their sense of being master and form a safe and steady education base, and make cultural construction and student management come into effect.

\section{Timely Guidance for Psychological Development}

In the key point of college Students' psychological growth, they can give timely and proper help and guidance, and the effect is obvious. For freshmen, carry out psychological investigation through the mental health education system, establish a psychological health file and help them to adapt as soon as possible. Strengthen communication and guidance. For graduates, actively learn and master the psychological status of college students through exchanges. Track and care graduates who have the tendency of psychological crisis or are in psychological crisis, and timely and effectively give them target positioning and analysis, and help them develop toward correct direction. In short, fine management can help counselors grasp the key points of each student well, communicate with students in time, appreciate students and help them grow.

\section{Moving toward the Professional Level}

To implement fine management helps construct a standard and professional counselor team. Counselors shall not only manage student work meticulously but also be diligent in research and innovation to gradually improve their own scientific research capabilities. Under the guidance of the concept of fine management, counselors can use scientifically make in-depth research, analysis and summary o students and society based on occupation ability standard of college counselors and the growth law of students, so as to improve their the level of experience of counselors to a certain degree and move toward professional level.

\section{CONCLUSION}

Education has no trivial matter and education can be everywhere. Education on college students is realized through a large number of daily, trivial, complex and repeated work. So we can use fine management to form an effective working methods and ideas, and promote the transformation and improvement of counselors' thinking habits, values, cultural atmosphere and team construction of teachers. It will promote the overall development of the school and achieve the goal of educating people in an all-round way to strengthen the fine management concept of counselors.

\section{REFERENCES}

[1] Wang Zhongqiu, Wu Hongbiao \& Liu Xingwang. Fine Management. Xinhua Publishing House, 2005.

[2] Yang Xiangui \& Zhang Changmin. Fine Management and Refinement of University Management. Shanghai Science Management, 2008 (2): 82-83. 
[3] Zhou Lixin. Construction of High-quality College Counselors. Research on Ideological and Political Work, 2006 (8): 43.

[4] Chen Xuan. Analysis of the Work of College Counselors in Fine Management Mode. New West (Late. Theoretical Edition), 2011 (2).

[5] Zhang Bihua, Yao Zuchan \& Zheng Yuchen. Analysis of the Necessity and Feasibility of Fine Management of Student Work in Independent College. Research on Ideological and Political Education, 2011 (4): 120-121.

[6] Zhang Lifang. Fine Management of College Counselors Work in the New Era. Journal of Yangtze University (SOCIAL SCIENCE EDITION), 2011 (7).

[7] Chen Fei. Enlightenment of Fine Management on the Work of College Counselors. Journal of Inner Mongolia Agricultural University (SOCIAL SCIENCE EDITION), 2010 (5).

[8] Yue Hua. Study and Practice on the Long-term Mechanism of College Counselor Team Construction. Journal of Liaoning Technical University (SOCIAL SCIENCE EDITION), 2011 (5). 